\title{
SERTOLI LEYDIG CELL TUMOUR OF THE OVARY WITH SPORADIC MULTINODULAR GOITER: A RARE CASE REPORT
}

\author{
Kavitha Karthikeyan'1, A.P. Nalini² ${ }^{2}$ Prabha Swaminathan ${ }^{3}$
}

HOW TO CITE THIS ARTICLE:

Kavitha Karthikeyan, A P Nalini, Prabha Swaminathan. "Sertoli leydig cell tumour of the ovary with sporadic multinodular goiter: A Rare Case Report". Journal of Evolution of Medical and Dental Sciences 2013; Vol2, Issue 33, August 19; Page: 6356-6359.

ABSTRACT: Sertoli Leydig cell tumour also called arrhenoblastoma is a rare type of sex cord stromal tumour of the ovary. They constitute less than $0.5 \%$ of ovarian cancers (3).They are characterized by the presence of testicular structures that secrete androgens. Patients present with symptoms of virilisation depending on the androgen production. Familial multinodular goitre with Sertoli Leydig cell tumour has been associated with mutations of DICER 1 gene (1). In young females, fertility sparing surgery is the best option for non metastatic tumours.

KEY WORDS: Sertoli Leydig cell tumour, multinodular goiter, virilisation, arrhenoblastoma

INTRODUCTION: This is the report of a young patient of 20 years of age who presented with secondary amenorrhea, virilisation, multinodular goitre and abdomino pelvic mass. She was diagnosed as a case of androgen secreting ovarian tumour and was treated by unilateral salpingo oophorectomy. Histopathological examination revealed a Sertoli leydig cell tumour. There was no recurrence at 6 months and testosterone levels had returned to normal. Most of these tumours are unilateral and confined to the ovary (7). They occur during the third and fourth decades of life. Virilisation is noted in $70 \%-80 \%$ patients. They are frequently low grade malignancies. Poorly differentiated forms with heterologous elements have an aggressive course. (1).The presence of familial multinodular goitre necessitates scrutiny for gonadal tumours and pleuro pulmonary blastoma in the family members

CASE REPORT: 20 year old unmarried female presented to the outpatient department with secondary amenorrhea for a period of 1.5 years, lower abdominal distension for 4 months and lower abdominal pain for 1 month. She had previous regular menstrual cycles with normal flow, then oligomenorrhea for a period of 8 months followed by amenorrhea. She had hoarseness of voice and weight loss which developed over a year. She was a known hypothyroid patient on treatment for the past 8 months. There was no family history of goitre or ovarian tumours.

On examination, she was thin built (BMI - 19.1), hirsute and had multinodular goitre. Examination of the abdomen showed a mass arising from the pelvis upto the level of umbilicus measuring $15 \times 12 \mathrm{~cm}$ extending $9 \mathrm{~cm}$ to the left and $6 \mathrm{~cm}$ to the right of midline. The mass had a firm consistency, smooth surface, well defined borders, restricted mobility and no tenderness. There was no ascites. On bimanual pelvic examination the uterus was anteverted, mobile and of normal size. The mass was felt separately from the uterus. Local examination of the genitals showed clitoromegaly. A provisional diagnosis of left ovarian androgen secreting benign tumour was made.

The reports of routine preoperative blood investigations were normal including thyroid function tests, prolactin and DHEAS, except testosterone which was raised $(2.11 \mathrm{ng} / \mathrm{ml})$. Tumour markers were negative. USG abdomen showed a well defined midline mass extending upto the 
umbilicus measuring 15.4 x $13.1 \mathrm{~cm}$ with multiple thin walled clear cysts of varying sizes interspersed with echogenic tissue arising from left ovary. Right ovary and uterus were normal. Endometrial thickness was $5 \mathrm{~mm}$.No free fluid was noted. Liver, gallbladder, pancreas, spleen, kidney appeared normal. CT abdomen and pelvis confirmed the diagnosis of left ovarian tumour. There was no lymphadenopathy or any other evidence of metastasis.

TREATMENT : Patient was taken up for laparotomy and after taking a sample of peritoneal washings ,a tumour of $15 \times 13 \mathrm{~cm}$ with multiple solid and cystic areas with intact capsule arising from left ovary with the left fallopian tube was removed. Frozen section was suggestive of sex cord stromal tumour. Then we proceeded with infracolic omentectomy, multiple peritoneal biopsies, left common iliac lymphadenectomy and finally biopsy from the right ovary.

The post- operative period was uneventful .The histopathology report came out to be well differentiated Sertoli leydig cell tumour. The other structures showed no metastatic deposits and it was considered stage 1tumour. Oncologist opinion was obtained and he suggested regular follow up. The patient was followed up after a month and every 3months for 1 year. She resumed regular menstrual cycles 3 months after surgery. Repeat testosterone levels were normal

DISCUSSION: Our case is a low grade Sertoli leydig cell tumour (SLCT) presenting in a young female. Very few cases of (SLCT) co existent with multi nodular goiter have been reported mostly as familial (2). Germline mutations of DICER 1 gene that code for RNase III endoribonuclease has been identified in families having multinodular goiter with pleuro-pulmonary blastoma and gonadal tumours like SLCT (1). Ours is a sporadic case of multi nodular goitre with coexistent sertoli leydig cell tumour. The leydig cells secrete testosterone frequently and sometimes dehydroepiandrosterone sulphate. SLCT does not produce elevated tumour markers. They are classified as benign and malignant depending on the degree of differentiation (4).According to WHO, they are classified into well differentiated, intermediately differentiated, poorly differentiated and tumours with heterologous elements.

The tumours with heterologous elements contribute to $20 \%$ of SLCT and have the most malignant potential (4).They can be of the endodermal or mesenchymal elements. Somatic missense mutation FOX L 2 is expressed in 50\% of SLCT. A hereditary predisposition to the occurrence of the tumour has been reported. Immunohistochemistry is useful in diagnosis.

Abdominal hysterectomy with bilateral salpingo oophorectomy is the surgery of choice in older patients. The tumour is rarely bilateral and in young patients unilateral salpingo oophorectomy with biopsy from the contralateral ovary is the preferred option with the aim of conserving fertility (6). The tumour can also be laparoscopically removed. (5)

The most important prognostic factors are the stage of the tumour at diagnosis and the degree of differentiation in histopathological examination. The role of post operative radiation and chemotherapy is not well established. Patients with evidence of metastasis or poorly differentiated tumours have been treated with pelvic irradiation and Vincristine, Actinomycin D, Cyclophosphamide chemotherapy regimen with better responses (6). Our patient had a well differentiated SLCT which is reported in $30 \%$ patients. No post operative chemotherapy was required for our patient. The presence of goitre does not influence the modality of treatment. The average 5 year survival rate is $70 \%-90 \%$ 


\section{CASE REPORT}

CONCLUSION: SLCT is a rare sex cord stromal tumour that occurs unilaterally. It should be considered in patients with ovarian mass presenting with features of virilisation. Presence of coexistent multinodular goitre should provoke one to investigate for familial SLCT.

\section{REFERENCES:}

1. RiofrioT, Bahubeshi A, Kanelloupolou C, Hamel N: DICER 1 mutation in familial multinodular goiter with and without sertoli leydig cell tumour ,JAMA 2011, Jan 5 ;305(1) 68-77

2. Chi M, Gilman AD, Irogbu N: Management of metastatic ovarian SLCT with sporadic multinodular goiter. Future oncol. 2011 Sep 7(9) 1113-7

3. DiSaia PJ, Creasman WT. Germ cell, stromal and other ovarian tumors. In: Clinical Gynecologic Oncology, Mosby-Yearbook, 1997. p.351.

4. Dietrich JE, Kaplan A, Lopez H, Jaffee I.A case of poorly differentiated Sertoli- Leydig tumour of the ovary. J Pediatr Adolesc Gynecol. 2004;17:49-50

5. Kriplani A, Agarwal N, Roy KK, Manchanda R, Singh MK. Laproscopic management of SertoliLeydig cell tumours of the ovary. A report of two cases. J Reprod Med. 2001;46:493-496

6. Sood AK, Gershenson DM. Management of early-stage ovarian cancer. In: Bristow RE, Karlan BY, editors. Surgery for Ovarian Cancer: Principles and Practice. London, UK: Taylor and Francis; 2005. pp. 57-86.

7. Rimpy Tandon, MD, Poonam Goel, and RPS Punia, sertoli leydig cell tumour with heterologous element, Med Gen Med, 2007: 9(44)

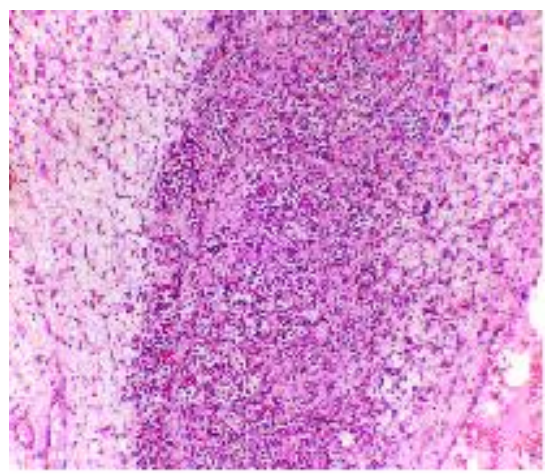

Fig 1 microscopic appearance of sertollileydig cell tumour of ovary.Theleydig cells have abundant eosinophillliccytoplasm.Sertolli cells have pale cytoplasm

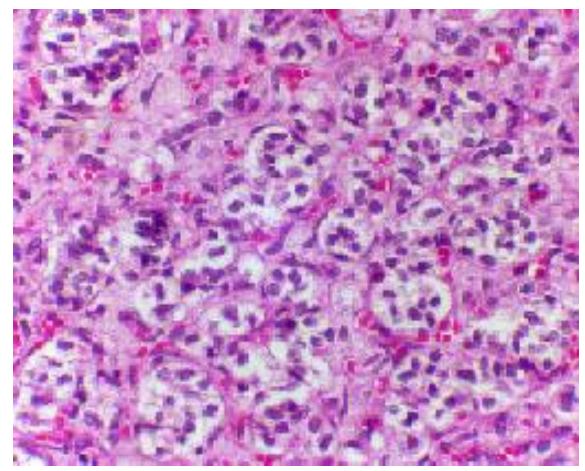

fig 2 High power view of the tumour showing cords and tubules of sertolli cells with leydig cells 


\section{CASE REPORT}

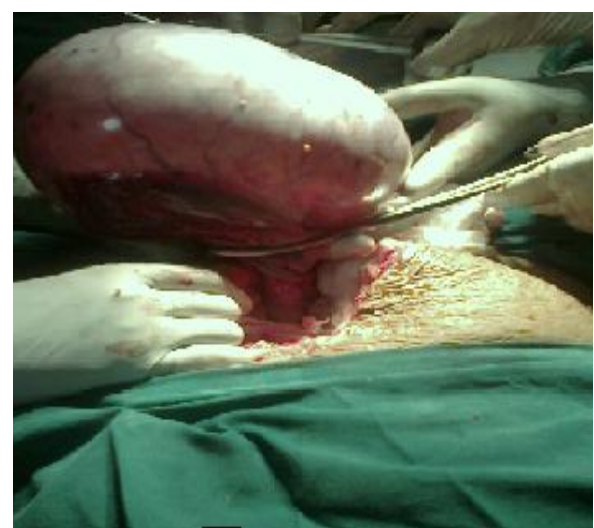

Fig 3 Gross intra operative appearance of the ovarian tumour

\section{AUTHORS:}

1. Kavitha Karthikeyan

2. A.P. Nalini

3. Prabha Swaminathan

\section{PARTICULARS OF CONTRIBUTORS:}

1. Assistant Professor, Department of Obstetrics and Gynaecology, Chettinad Hospital and Research Institute.

2. Professor, Department of Obstetrics and Gynaecology, Chettinad Hospital and Research Institute.

3. Assistant Professor, Department of Obstetrics and Gynaecology, Chettinad Hospital and Research Institute.

\section{NAME ADDRESS EMAIL ID OF THE} CORRESPONDING AUTHOR:

Dr. Kavitha Karthikeyan,

Flat B1, Aishwarya Agasthiya 1,

Guindy Engineers Colony, Okkiyum,

Thoraipakkam, Chennai.

Email- kavikarthik16@yahoo.com

Date of Submission: 07/08/2013.

Date of Peer Review: 08/08/2013.

Date of Acceptance: 16/08/2013.

Date of Publishing: 19/08/2013 